\title{
Проблемы оптимизации цепочек поставок подрядчиков Пентагона
}

\author{
М. Макушин ${ }^{1}$, А. Фомина, д. э. н. ${ }^{2}$
}

УДК 658.785 | ВАК 05.13 .10

\begin{abstract}
Функционирование цепочек поставок оказывает значительное влияние на успех или провал производителя конечной продукции в плане своевременного вывода на рынок новых электронных компонентов, подсистем и систем. В статье рассматриваются основные препятствия на пути формирования успешных цепочек поставок и мер их преодоления. Также затронут вопрос практики подрядчиков МО США по оптимизации своих цепочек поставок, трансформационный подход консалтинговой фирмы Boston Consulting Group и планы ВВС США по совершенствованию закупочно-эксплуатационной деятельности.
\end{abstract}

существление любой производственной деятельности требует налаживания цепочек поставок. Они включают в себя поставки сырья и материалов, деталей и узлов, аутсорсинговых услуг проектирования, сборки, корпусирования и тестирования, а также внешнюю разработку программного обеспечения. В составе этих цепочек находятся поставщики первого, второго и третьего уровней, при этом они взаимосвязаны не только с конечным потребителем их продукции и услуг, но и друг с другом. Получается сложная, "трехмерная" система, и чем она сложнее, тем выше затраты на нее в структуре себестоимости конечной продукции. Более того, чем сложнее цепочка поставок (а ее сложность непосредственно связана со сложностью конечной продукции), тем выше риски ее нарушений. В свою очередь, любые сбои в цепочке приводят к срыву графика вывода на рынок конечной продукции.

Соответственно, перед конечными изготовителями, особенно в оборонном секторе, стоят задачи оптимизации цепочек поставок с целью как повышения их надежности, так и снижения издержек. На пути формирования успешных цепочек поставок существуют различные препятствия, при этом существуют и отработанные рецепты их преодоления. Но их не всегда удается реализовать. Подрядчики Пентагона в последнее время активно работают в этом направлении и в некоторых случаях добиваются успехов. В этом им помогают различные консалтинговые фирмы (например, Boston Consulting Group), разрабатывающие подходы к оптимизации цепочек поставок. С другой стороны, МО США также ищет пути совершенствования своих цепочек поставок, но со стороны закупки и технического обслуживания.

ЦНИИ «Эектроника», главный специалист, mmackushin@gmail.com Цнии «Электроника», генеральный директор.
ПРЕГРАДЫ НА ПУТИ УСПЕХА ЦЕПОЧЕК ПОСТАВОК Оборонная промышленность во всем мире сталкивается с новыми вызовами, в том числе с тем, как обеспечить рост прибыли в условиях потенциального падения рынка и как сократить расходы на поддержание приемлемых финансовых показателей. Мерами, обычно принимаемыми в таких ситуациях, являются сокращение штатов и накладных расходов, что приводит к увеличению операционных доходов на одного сотрудника. Также проводится автоматизация процессов и оптимизация цепочек поставок. Наступление цифровой эры, разработка цифровых продуктов и автоматизированное проектирование привели к повышению эффективности процесса разработки и производства электронных компонентов, систем и услуг

Тем не менее на пути построения успешной цепочки поставок стоит как минимум семь препятствий

\section{Многочисленность ERP}

Различные точечные решения, наличие многочисленных систем планирования и управление корпоративными ресурсами (ERP - общее и структурированное планирование деятельности предприятия, управление финансами фирмы, управление кадрами, учет материальных ресурсов, учет и управление снабжением и сбытом, оперативное управление текущей деятельностью и контроль выполнения планов, документооборот предприятия, анализ результатов хозяйственной деятельности) и унаследованные системы", расположенные по всему миру, подразумевают разрозненность и несвязанность данных. Это приводит к плохой сквозной видимости цепочки поставок,

\footnotetext{
Legacy systems - унаследованные системы, то есть системы, переставшие удовлетворять потребностям применений, но все еще находящиеся в эксплуатации из-за трудностей их замены, так как при проектировании таких систем не были заложены возможности их перестройки
} 
задержке в принятии важнейших решений и общей неэффективности операций цепочки поставок.

Решение проблемы: включение всех данных по спросу и предложению в замкнутый цикл, который передается обратно в исполнительные системы сучетом решений, принятых в течение всего цикла планирования. Интеграция данных в единую систему учета укрепляет доверие к точности данных и глобальной системе управления производственными мощностями. Единый набор данных означает единственную достоверную версию ситуации.

\section{Требования к крупномасштабным данным}

Огромный объем вычислительных мощностей, необходимых для моделирования глобальных многоуровневых цепочек поставок и увеличения спроса и предложения в рамках интегрированных цепочек поставок. Критической возможностью успешности цепочки поставок является способность к масштабированию.

Решение: необходимо убедиться, что для поддержки требований к масштабируемости и производительности объекта с интенсивным использованием данных применяются лучшие из доступных технологий.

\section{Сложность цепочки поставок}

Ограниченная наблюдаемость вследствие возросшей сложности цепочки поставок затрудняет понимание реального положения дел в расширенной сети создания добавленной стоимости. Это касается таких аспектов, как производственные мощности, наличие материалов и вероятность поддержки при сдвигах графиков разработки, производства, поставок и т.д.

Решение: соединение сквозной цепочки поставок путем согласования данных в едином источнике информации, что позволит улучшить наблюдаемость и даст представление о планируемом и текущем спросе/предложении, товарно-материальных запасах, производственных мощностях, емкости рынка и ограничениях на любом желаемом уровне иерархии изделий.

\section{Сложность продукции}

Продукция обычно характеризуется большим числом доступных моделей, опций и конфигураций. Соответственно продолжают поступать заказы на технические изменения с целью подстройки под индивидуальные потребности каждого заказчика. Это приводит к возникновению большого числа разнообразных спецификаций, которые должны учитывать множество атрибутов планирования, включая эффективность продукции, определение приоритетов, объединение товарно-материальныхзапасов, взаимозаменяемость частей и всех элементов ведомостей материалов (подробная опись всех сырьевых материалов и компонентов, из которых изготовлен продукт, с указанием иххарактеристик и количеств).
Решение: комплексная аналитическая поддержка. Решения, поддерживающие все параметры планирования в аэрокосмической и оборонной промышленности в области спроса, предложения, товарно-материальных запасов и приведения производственных мощностей в состояние равновесия. Спецификации должны содержать структуру производимой продукции и характеристики каждого из производимых изделий, даты начала и окончания работы, выход годных и ряд других факторов. Это приводит к взрыву спроса на данные по всей структуре продукции сверху донизу. Эффективное управление различными группами товарно-материальных запасов должно обеспечивать предотвращение их смешивания по каждому типу изделий, связанных с различными клиентами, контрактами или проектами. Также необходимо сгруппировать вместе изделия, считающиеся эквивалентными по форме и функции, чтобы удовлетворить спрос на любую деталь во взаимозаменяемых группах. Крометого, требуется установить различные уровни приоритета, это гарантия того, что заказы с более высоким приоритетом обслуживаются в первую очередь.

\section{Адекватные инструментальные средства моделирования}

Существующие инструментальные средства моделирования изменений в графиках осуществления работ требуют большого опыта эксплуатации и не в полной мере отражают существующие в рамках расширенной цепочки поставок ограничения. Корректировка показателей может занять очень много времени, в некоторых случаях до нескольких недель.

Решение: развернуть инструментальные средства, позволяющие тестировать изменения показателей за секунды. Благодаря этому можно будет сразу же увидеть влияние изменений на всю цепочку поставок, сроки реализации различныхпроектов, принятие решений о назначении конкретных сроков и производственные мощности, а также быстро пригласить пользователей принять участие в решении любых проблем. Возможности анализа "что / если» (моделирование будущих результатов при различных вариантах развития событий) и создания различных сценариев также позволяют ускорить упрощение процедур и обеспечить широкое сотрудничество для обеспечения согласования графика и достижения практической осуществимости.

\section{Анализ сбалансированности}

Высокая степень индивидуальной конфигурируемости элемента цепочки поставок обуславливает высокую потребность в наблюдаемости - для обеспечения выравнивания схемы поставок и возможности обеспечить своевременную поставку каждого элемента. Кроме того, наблюдаемость требуется для прогнозируемости достижения дохода. К сожалению, наблюдаемость не всегда возможна. 
Решение: объединить данные, процессы и персонал в единую, гармоничную среду. Такая среда позволит легко наблюдать весь набор электронных компонентов, подсистем и систем, включая источник поставки (в наличии, по заказу или по плану), необходимых для производства авиакосмических и военных систем. Это позволяет определить, все ли необходимые электронные компоненты, подсистемы и системы в наличии и будет ли возможность поддерживать окно доставки клиента (время доставки конечной продукции, приемлемое для клиента).

\section{Технические изменения}

Технические изменения являются обычным явлением, и поскольку эти изменения часто появляются в нескольких системах, трудно оценить влияние на цепочку поставок.

Решение: тестирование и определение конкретных технических изменений на определение дат выполнения операций в цепочке поставок. Это позволяет повысить эффективность принятия решений и избежать ситуаций выделения избыточных или недостаточных ресурсов [1].

\section{НОВЫЕ ПОДХОДЫ ПОДРЯДЧИКОВ ПЕНТАГОНА К СОКРАЩЕНИЮ ИЗДЕРЖЕК}

При разработке и внедрении вооружений/систем вооружений большое значение имеет сокращение издержек и сроков разработки. В последнее время оборонная промышленность США демонстрирует новые подходы в этом плане. Основное - это сокращение цепочки поставок, исключение из нее необязательных звеньев.

Растущая конфликтность на мировой арене привела к существенному росту военного бюджета США. При этом сохраняется тенденция увеличения трат на высокотехнологичные вооружения и технические средства. Это дает производителям и подрядчикам Пентагона большие возможности для увеличения производства и развития инновационного процесса.

Одним из выгодных моментов для американской оборонной промышленности является то, что руководство страны и вооруженных сил отдают предпочтение внутреннему производству. Тем не менее растущие расходы на разработку и производство новых вооружений заставляют искать пути снижения их себестоимости без ущерба для качества. На увеличение издержек военных подрядчиков, в частности, влияет рост цен на нефть и некоторые другие виды сырья и товары.

Одним из направлений усилий в данной области является совершенствование цепочки поставок. Это, в частности, обусловлено требованиями правительства по использованию военными подрядчиками продукции и услуг малых предприятий, повышению эффективности производственных процессов, что обеспечивает экономию средств и сокращает время вывода на рынок новой продукции.

\section{Сокращение издержек}

При внедрении новых технологий всегда существует фактор необходимости снижения издержек. В частности, это обусловлено тем, что конкуренция за получение военных подрядов является очень интенсивной и для выигрыша контракта одним из основных условий является способность поставщика снижать издержки. К существенной экономии может потенциально привести не столько работа с поставщиком по сокращению затрат, сколько переосмысление всей цепочки поставок.

Например, во время интеграции в стойку вычислительной техники, средств связи и других устройств конечный пользователь обычно указывает поставщика аппаратного обеспечения, а затем выбирает системного интегратора, осуществляющего сборку оборудования и систем, указанных клиентом, в стойку с определенными структурированными кабелями, салазками и управлением кабелями.

Перспективные подходы заключаются в том, что в новой модели поставщик оборудования также становится и системным интегратором, что обеспечивает экономию затрат примерно на 20\% для конечных пользователей и основных подрядчиков МО США. При этом обеспечивается сокращение времени исполнения заказа и улучшается общая совместимость систем и оборудования.

\section{Сокращение сроков исполнения заказа}

Переосмысление цепочки поставок приводит не только к сокращению издержек, но и способствует ускорению разработки новой продукции военного назначения. С ростом сложности оружейных платформ многие подрядчики с целью ускорения процесса обработки обращаются к коммерчески доступным изделиям (COTS").

При этом даже в рамках COTS-предложений есть возможности удаления ненужных этапов из цепочки поставок, что позволяет подрядчикам Пентагона сократить время исполнения заказов и устранить проблемы с конфигурацией. Отпадает необходимость взаимных отгрузок компонентов между поставщиком оборудования и системным интегратором, что позволяет сократить число посредников, необходимых в процессах производства и сборки.

Кроме того, совместимость между различными компонентами в каждой приборной стойке в определенной степени гарантируется, так как все компоненты производятся/ подбираются и собираются одним поставщиком оборудования. Это также позволяет сократить время, затрачиваемое на устранение проблем совместимости. Выбрав поставщика оборудования, способного интегрировать комплексные решения в области приборныхстоек, крупнейшие подрядчики МО США могут снизить время разработки новых вооружений и систем вооружений.

cOTS (commercial off-the-shelf) - приобретаемый в готовом виде на коммерческом рынке. 
18-я МЕЖДУНАРОДНАЯ В ЫСТАВКА ЭЛЕКТРОНИКИ
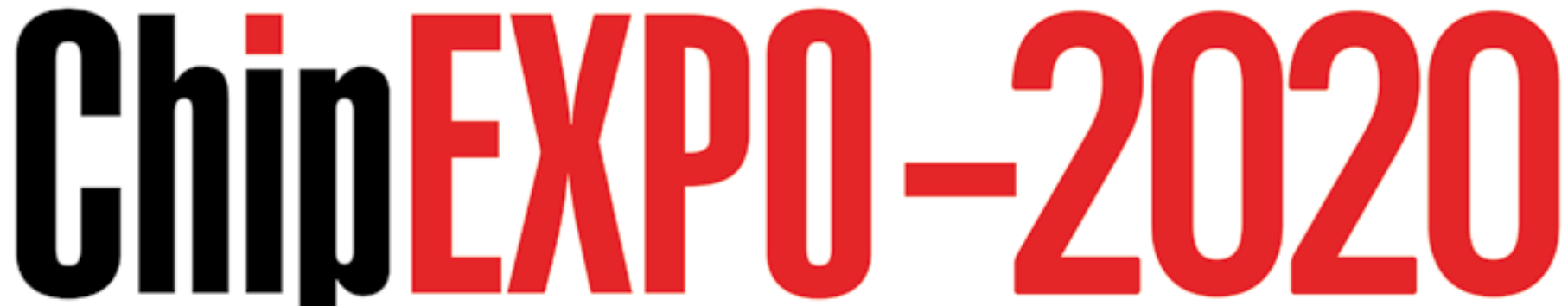

\section{КОМПОНЕНТЫ | ОБОРУДОВАНИЕ | ТЕХНОЛОГИИ}

\section{ВЫСТАВКА ПРОЙДЕТ}
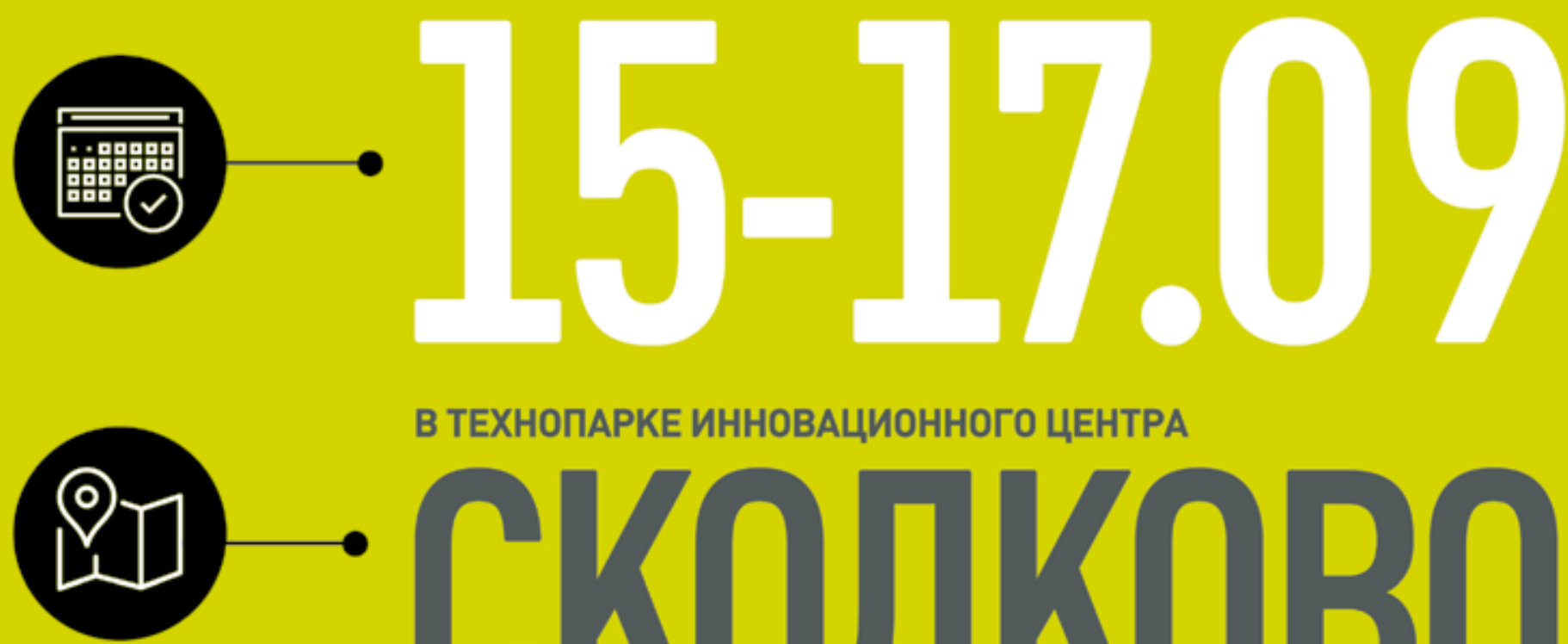

\section{В ТЕХНОПАРКЕ ИННОВАЦИОННОГО ЦЕНТРА}
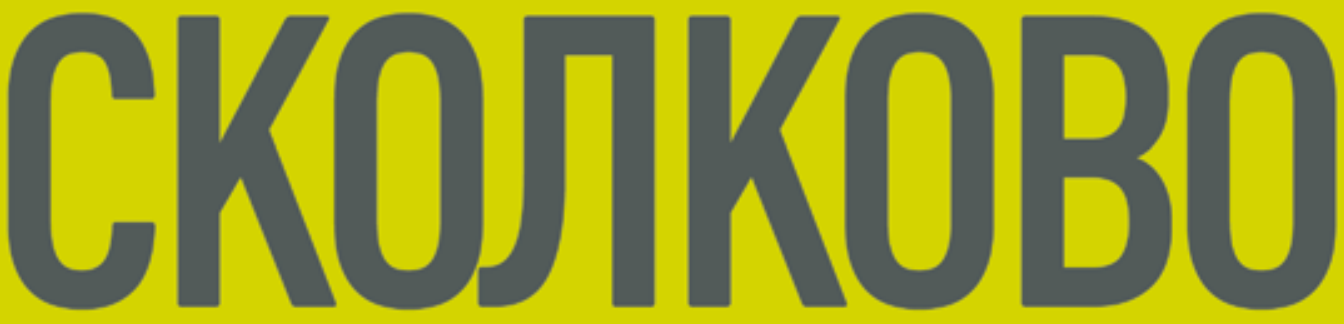

\section{ТЕМАТИЧЕСКИЕ ЭКСПОЗИЦИИ:}

- Экспозиция Департамента радиоэлектронной промышленности Минпромторга России, включая:

- экспозицию предприятий, являющихся изготовителями изделий, включенных в единый реестр российской радиоэлектронной продукции (Постановление Правительства РФ №878), - экспозицию разработок, созданных в рамках государственной программы

«Развитие электронной и радиоэлектронной промышленности на 2013-2025 годы»

[Постановление Правительства РФ №109],

- экспозицию разработок, обеспечивающих выполнение приоритетных национальных проектов.

- Дивизионы кластера

«Радиоэлектроника» ГК «Ростех»

- Стартапы в электронике

- Квалифицированные поставщикии ЭКБ

- Консорциумы и дизайн-центры по электронике

- Участники конкурса «Золотой Чип»

- Корпорация развития Зеленограда

ОФИЦИАЛЬНАЯ ПОДДЕРЖКА:
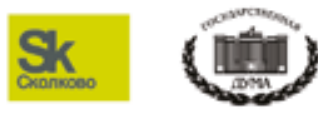

минпромторг 人 России $\mathrm{O}_{\text {росэм }}$

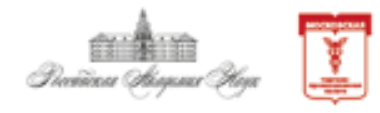

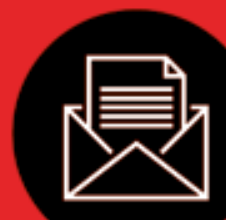




\section{Повышение качества и совместимости}

Еще одним преимуществом ситуации, когда поставщик аппаратного обеспечения интегрирует всю приборную стойку, является совместимость и управление качеством. Компоненты и подкомпоненты номеруются по единому классификатору, каждая система обеспечивается возможностью управления устареванием и контролем долгосрочной поддержки в течение всего срока действия программы использования вооружений/систем вооружений. Конечные пользователи извлекают значительные выгоды из консолидации системного интегратора и производителя компонентов. Управление цепочкой поставок с использованием единого классификатора обеспечивает ускорение переупорядочивания компонентов и исправления выявленных неисправностей. Процесс долговременной поддержки и модернизации военных систем упрощается благодаря снижению вероятности возникновения проблем совместимости компонентов, поскольку каждый компонент производится одним и тем же производителем.

Изменение приоритетов и переход от поддержания оперативной готовности развернутых сил к их модернизации обеспечит сокращение расходов и сроков исполнения контрактов. Это уже в ближайшем будущем может способствовать повышению максимизации эффективности оборонных бюджетов [2].

\section{ТРАНСФОРМАЦИОННЫЙ ПОДХОД ВОЛТОN CONSULTING GROUP}

То, что генеральные подрядчики Пентагона должны осваивать новые подходы к сокращению издержек, связанных с цепочкой поставок, является очевидным фактом. Условия ведения бизнеса американскими военными подрядчиками за последние несколько лет стали более проблематичными. Пересмотр и сокращение числа финансируемых программ (при общем росте военных ассигнований) ограничили рост оборонной промышленности, создав всепроникающую динамику «победитель получает все».

Традиционные подходы к совершенствованию производственно-сбытовых цепочек недостаточны для решения этих проблем. Любая попытка поставщика снизить свои затраты за счет конечного потребителя - это гарантированный способ потерять бизнес в ожесточенной конкурентной борьбе. Разрозненные усилия внутрикорпоративных функциональных групп и жесткое применение методологии "один размер подходит всем" приводят в лучшем случае к постепенным улучшениям и единовременным выгодам. Чтобы оставаться конкурентоспособными, основные подрядчики должны принимать меры по систематическому снижению затрат в цепочке поставок.

Международная консалтинговая компания Boston Consulting Group (BCG) представила опробованный трансформационный подход (см. рисунок), обеспечивающий устойчивое улучшение управления цепочками поставок. Эта структура основана на конкретных базовых проблемах производительности и текущих уровнях зрелости цепочки поставок. С его помощью ВСС помогает клиентам распознавать источники риска цепочки поставок и разрабатывать планы смягчения последствий для получения прибыли. Возможности цепочки поставок повышаются за счет целенаправленного развертывания обучения и инструментария управления.

Используя подход к управлению своими источниками и цепочками поставок, носящий более стратегический характер, подрядчики могут сократить издержки, освоить

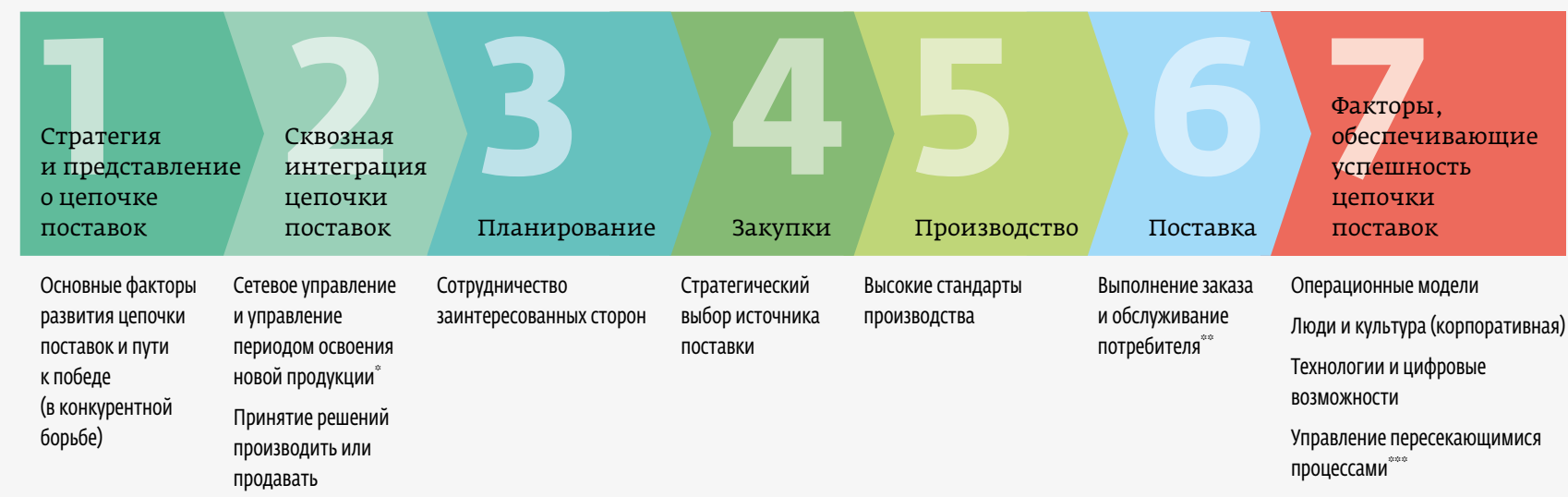

\footnotetext{
Период освоения новой продукции - начинается с изготовления опытного образца и завершается серийным производством продукции .

Взаимодействие с потребителем на всех стадиях жизненного цикла продукции.

Процессы, в ходе которых разные группы сотрудничают для осуществления важных для всех групп функций, таких как обучение, стимулирование продаж и т. д.
}

Рис. 1. Блок-схема методики консалтинговой фирмы Boston Consulting Group по улучшению управления цепочкой поставок подрядчиков МО США 


\section{Обустройство нефтегазовых месторождений технический форум}

\section{Главная цель форума -}

представить и обсудить современные принципы и технологии обустройства наземных и морских месторождений нефти и газа для эффективной разработки.

\section{Темы Форума}

- Технологическое проектирование объектов обустройства месторождений и первичной подготовки и переработки продуктов добычи.

- Подготовка концептуального проекта разработки и обустройства нефтегазовых месторождений.

- Технико-экономические расчеты при проектировании обустройства нефтегазовых месторождений.

- Расчеты при оценке стоимости капитального строительства.

- Блочно-модульное исполнение основного технологического оборудования. Примеры блочных поставок.

- Информационные технологии в проектировании обустройства.

Рассмотрение методологии создания моделей.

- Разработка и освоение морских месторождений.

- Подводные добычные комплексы.

- Оборудование и технологии обеспечения морской добычи.

- Другие темы отрасли.

\section{Возможности для вашего продвижения на рынке}

Форум и выставка привлечет в качестве участников ключевых менеджеров компаний, что обеспечит вам, как партнеру Форума, уникальные возможности для встречи с новыми заказчиками. Большой зал будет удобным местом для размещения стенда вашей компании. Выбор одного из партнерских пакетов позволит Вам заявить о своей компании, продукции и услугах, и стать лидером быстрорастущего рынка.

Для дополнительной информации и подбора решения, удовлетворяющего Вашим задачам и бюджету, пожалуйста свяжитесь с нами по электронной почте info@forumneftegaz.org или по телефону +7 (495) 488-6749.

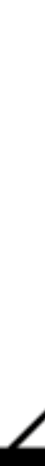


новые направления деятельности и улучшить свои финансовые показатели на рынке с постоянно обостряющейся конкуренцией [3].

\section{ПЛАНЫ ВВС США}

С другой стороны, МО США также ищет пути совершенствования своих цепочек поставок, но со стороны закупки и технического обслуживания. Новая Стратегия национальной обороны США - это маршрутная карта новой точки зрения МО США на Россию и КНР, бросающих вызов доминированию ВС США за счет быстрого развития новых технологий. В ВВС США поставленные в маршрутной карте задачи решаются многими способами, включая сокращение сроков разработки новых технологий, возрождение культуры инноваций и переосмысление подхода к будущим конфликтам. Поскольку планируется сдерживать и, в случае необходимости, побеждать будущих противников, важно проявление гораздо большей гибкости в сферах разработки и закупки оружия.

Одним из важных вопросов в будущем станет отношение к правам интеллектуальной собственности при закупках оружия. Исторически сложилось так, что подрядчики МО США обладали правами интеллектуальной собственности на широкий спектр вооружений: от истребителей до ракет и дистанционно пилотируемых летательных аппаратов. Обладание правами интеллектуальной собственности, как правило, дает производителям военных систем почти исключительный контроль над модернизацией технологий в течение всего срока эксплуатации (иногда до нескольких десятилетий), когда многие виды систем вооружений остаются на складском хранении.

Эта бизнес-модель обеспечила постоянную рентабельность подрядчиков Пентагона за счет того, что по крупным контрактам на вооружения/системы вооружений итоговые выплаты часто перекрывают начальную цену. Это перекрытие обеспечивается за счет работ по техническому обслуживанию и модернизации, при этом все это осуществляется только тем поставщиком, с которым был заключен контракт. Такая ситуация мешает другим фирмам конкурировать за модернизацию вооружений/систем вооружений.

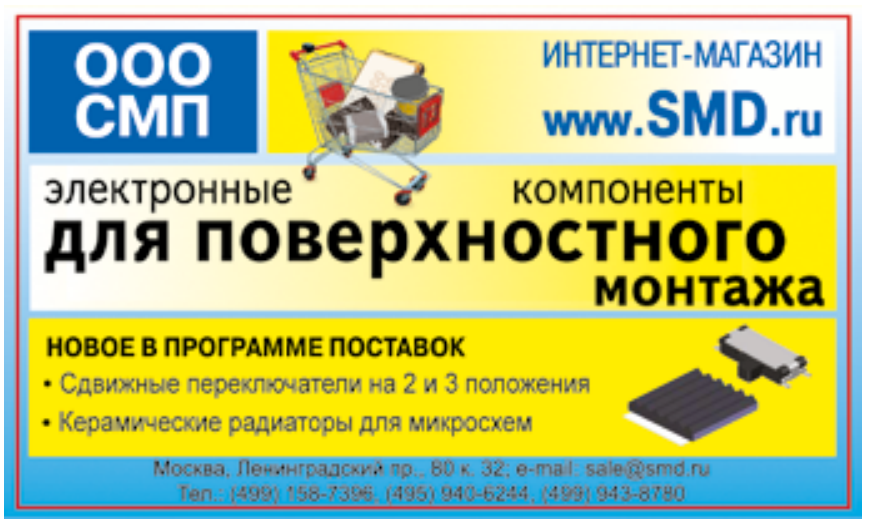

С целью решения этой проблемы Пентагон полтора года назад нанял комплексную группу специалистов в различных областях с тем, чтобы определить лучшие стратегии в области интеллектуальной собственности.

Реальность такова, что ВВС просто больше не могут позволить себе продолжать подобную практику закупок, если поставлена цель опередить компании России и Китая, быстро внедряющих инновации в таких областях, как квантовые вычисления, гиперзвуковые полеты и искусственный интеллект. Конгресс признал необходимость обеспечения большей гибкости и недавно принял закон, предусматривающий большую свободу действий МО США при разработке стратегий в области интеллектуальной собственности.

Изменить нынешнюю модель приобретения оружия будет трудно, но не невозможно. Цель ВВС - не обанкротить и не нанести вред американской промышленной базе, а создать новую модель, в которой подрядчики МО США смогут получать прибыль, а ВВС - извлекать выгоды расширения гибкости в области своей цепочки поставок. Такой вариант будет беспроигрышным. Одна из идей, которая уже обсуждается, заключается в том, чтобы платить больше за новое оружие при закупке, а права интеллектуальной собственности использовать позднее, чтобы значительно сократить расходы на содержание и обслуживание.

В общей стоимости любого вооружения / систем вооружений около 70\% связано с поддержанием после начала эксплуатации. Если вместо того, чтобы полагаться при модернизации сложной системы на фирму-поставщика можно было бы раскрыть творческий потенциал малых предприятий, стартапов и других, то объем вносимых в оборонные программы инновационных идей существенно вырастет

Специалисты ВВС считают, что такой же принцип может быть привнесен и в практику собственно закупки, а не последующего обслуживания вооружений/систем вооружений. Они представляют себе теоретическую ракету с открытой архитектурой и открытыми правами интеллектуальной собственности. Поскольку с течением времени требуется совершенствование этой ракеты, в рамках новой модели любая фирма сможет конкурировать за создание системы наведения, ПО или целеуказателя. Такая модель позволила бы снизить издержки, расширить промышленную базу и, по всей вероятности, улучшить вооружения/системы вооружений.

Таким образом, ВВС США желают обеспечить жизнеспособность военных подрядчиков и совместную работу с ними в рамках реализации стратегии "умной» интеллектуальной собственности. За счет этого предполагается обеспечить защиту прав интеллектуальной собственности на технические данные и ПО от их использования в своих целях иностранными государствами. Это должно позволить Америке оставаться мировым лидером в области 
искусственного интеллекта, аддитивного производства и профилактического обслуживания", а также снизить издержки .

Перспективность такого подхода хорошо иллюстрирует корпорация Apple. В 2010 году она представила планшетный ПК iPad, дальновидно позволив любой фирме создавать приложения для него. Это позволило инженерно-техническому персоналу и проектировщикам корпорации сосредоточиться на создании более совершенных iPad. Результатом стала способная к трансформации технология, улучшенная благодаря вкладу тысяч фирм, разработавших уникальные приложения от Google Earth до Netflix [4].

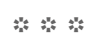

Совершенствование цепочек поставок крайне важно в условиях рынка с постоянно ужесточающейся конкуренцией. Это справедливо и для рынка вооружений/систем вооружений. Оптимизация этих цепочек способствует повышению их надежности, снижению издержек, повышению

\footnotetext{
Predictive maintenance - техническое обслуживание по те-

кущему состоянию, основанное на прогнозировании запаса надежности.
}

конкурентоспособности производителя конечной продукции. Опыт подрядчиков Пентагона, а также министерства ВВС США может быть интересен отечественным производителям.

\section{ЛИТЕРАТУРА}

1. Cheater A. 7 barriers to aerospace and defense supply chain success // Kinaxis blog, August 28 2017

https://blog.kinaxis.com/2017/08/supply-chain-pain-pointsaerospace-defense-industry/

2. McCormack M. A New Supply Chain for the Defense Industry // EE Times. 08.14.19 https://www.eetimes.com/document.asp?doc_id=1335035

3. Peddicor T., Juliano L. A New Supply Chain Strategy for Defense Contractors // BCG. August 23. 2019.

https://www.bcg.com/en-tr/industries/engineered-productsinfrastructure/supply-chain-strategy-for-defence.aspx

4. Ayres T.E. Changing how we buy weapons will benefit industry, government and taxpayers // Defense News. November 21. 2019.

https://www.defensenews.com/opinion/ commentary/2019/11/20/changing-how-we-buy-weaponswill-benefit-industry-government-and-taxpayers/?utm_ source $=$ clavis

\section{КНИГИ ИЗДАТЕЛЬСТВА «ТЕХНОСФЕРА»}

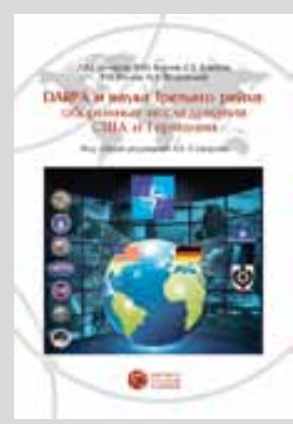

Цена 636 руб.

\section{DARPA И НАУКА ТРЕТЬЕГО РЕЙХА: ОБОРОННЫЕ ИССЛЕДОВАНИЯ США И ГЕРМАНИИ Под общ. ред. А. Е. Суворова}

В книге представлены материалы, содержащие анализ, обобщение и систематизацию опыта США и Германии, накопленного при организации, планировании, финансировании и проведении оборонных исследований. Выбор этих стран неслучаен и определен наличием существенных различий в процессах формирования и функционирования систем обеспечения вооруженных сил новейшими образцами оружия и военной техники. В целом, по мнению авторов, монография дает представление о функционировании системы оборонных исследований в США, а также опыте, накопленном в Германии в сфере управления НИОКР. При этом авторы не ставили себе целью охватить все аспекты зарубежного опыта по управлению исследованиями в интересах обороны и тем более дать исчерпывающие рекомендации по его использованию.

Вместе с тем материалы книги будут, безусловно, полезны широкому кругу специалистов, участвующих в процессах формирования, реализации и контроля исполнения как государственных, региональных и муниципальных программ развития, так и государственного оборонного заказа и программы вооружения. Надеемся, что найдут своего читателя и отдельные аспекты книги, касающиеся взаимодействия крупных промышленных предприятий, учреждений высшей школы, академической науки и предприятий малого бизнеса, а также механизмов привлечения научных институтов и малых предприятий к реализации крупных научно-технических проектов.

Материалы книги будут полезны широкому кругу специалистов, участвующих в процессах разработки и выполнения как государственного оборонного заказа и государственной программы вооружения, так и других государственных, федеральных целевых программ, имеющих оборонную направленность. Также книга может представлять интерес для руководителей государственных органов законодательной и исполнительной власти, работников промышленных предприятий, научных сотрудников академий наук и преподавателей учреждений высшей школы, изучающих организационные принципы и подходы к планированию крупных научно-технических проектов.

\section{КАК ЗАКАЗАТЬ НАШИ КНИГИ?}

$凶 125319$, Москва, а/я 91; +7 495 234-0110; 呾+7 495 956-3346; knigi@technosphera.ru, sales@technosphera.ru 